\title{
Dilemas estéticos e hermenêuticos da comunicação ${ }^{1}$ Aesthetics and hermeneutics dilemmas of communication
}

Jorge Cardoso Filho I jcunha@fafich.ufmg.br

Doutorando em Comunicação na UFMG, pesquisador dos grupos Poéticas da Experiência

e Mídia \& Música Popular Massiva, autor do livro Poética da Música Underground. Rio de Janeiro: E-papers, 2008. Bolsista CAPES/DAAD, na Universidade de Frankfurt, sob a supervisão do Prof. Martin Seel.

\section{Resumo}

$\mathrm{O}$ artigo mapeia o desenvolvimento de tendências no campo da Comunicação brasileira, no que diz respeito às abordagens de fenômenos da estética e da hermenêutica filosófica. A idéia de arte como acontecimento, fundamentada na perspectiva do filósofo Martin Heidegger e a tese da estética do aparecer, proposta pelo também filósofo Martin Seel, são examinadas a fim de apontar contribuições que essas noções podem trazer para o campo da Comunicação.

Palavras-chave: Estética da Comunicação; Hermenêutica; Filosofia.

\begin{abstract}
The paper outlines the development of tendencies in the field of Communication in Brazil, in regard to approaches from phenomena of the aesthetic and philosophical hermeneutics. The idea of art as an event, supported by the perspective of the philosopher Martin Heidegger, and the theory of aesthetics of appearing, proposed by Martin Seel, are examined in order to point out contributions that these notions can bring to the field of Communication.
\end{abstract}

Keywords: Communication Aesthetics: Hermeneutics; Philosophy. 


\section{Introdução}

No atual campo de estudos da Comunicação, no Brasil, ganhou força a discussão sobre os meios de comunicação e suas materialidades como mediaçôes da experiência partilhada, Guimarães \& Leal (2008), Valverde (2007a e 2007b) e Lopes (2008). Sobretudo a partir dos estudos das relaçôes entre formas de sentir e perceber com os aspectos técnicos e sociais é que o debate tem sido travado. Assim, na esperança de encontrar nas discussóes sobre a experiência, particularmente, sobre a experiência estética, os fundamentos para entender a experiência mediatizada, o olhar dos estudiosos da comunicação sobre a estética filosófica tem sido cada vez mais freqüente ${ }^{2}$.

Essa apropriação, evidentemente, não ocorre sem tensóes, uma vez que os conceitos e proposiçóes feitas no âmbito da filosofia são de difícil operacionalização na ainda muito recente tradição de estudos da Comunicação, sobretudo quando levamos em consideração a tendência analítica a partir da qual este campo se consolidou. $\mathrm{Na}$ disciplina filosófica do belo, o juízo sintético seria o que com menor prejuízo falaria da incomensurabilidade da experiência, sem pretensôes descritíveis, mas performativas. Tal reconhecimento é importante porque muitas vezes proposiçóes feitas no âmbito filosófico soam de uma forma diferente no campo da comunicação e uma tese de inspiração fortemente especulativa ganha uma força operacional que lhe seria totalmente avessa. $\mathrm{O}$ movimento oposto também é perigoso, uma vez que modelos de investigação sempre reduzem a experiência a um conjunto finito de variáveis.

Gostaríamos de propor o entendimento mais amplo sobre o tipo de incidência que as proposiçôes de um autor clássico da filosofia do século XX, como Heidegger, e um filósofo contemporâneo, como Martin Seel, podem trazer para a pensar a estética da comunicação, no contexto brasileiro. Possivelmente, esse mapeamento também ajudará a criar interseçôes com filósofos interessados em contribuir com o fortalecimento do campo da Comunicação.

Estamos preocupados em buscar na tradição filosófica o repertório no qual os discursos sobre a "estética da comunicação" têm se apoiado a fim de melhor atuar no debate em questáo, sobretudo no que diz respeito a pensar modos de apreensão da experiência.

\section{A arte como acontecimento em A origem da obra de arte}

Escrito em 1935, proferida em 1936 e publicada na Alemanha em 1950, o célebre ensaio sobre a origem da obra de arte, de Heidegger, não deve ser lido como um texto sobre "Estética", mas como continuação da interrogação heideggeriana sobre a história do ser, iniciada em 1927, com a publicação de Ser e Tempo. Abrindo sua obra com a pergunta sobre o sentido do Ser "was ist der Sinn von Sein?" e com a proposição de tomar a interpretação do Tempo como o horizonte de possibilidade de qualquer entendimento sobre o Ser, Heidegger recoloca a pergunta filosófica que "vale a pena ser feita".

O autor encontra, pelo menos, três motivos para recolocar essa questão: a primeira é que o conceito de ser é tomado como o mais ordinário - tanto na 
pergunta "o que é o ser?" quanto na resposta "o ser é..." a dimensão verdadeira do ser não é tematizada. O segundo motivo é, exatamente, a sua indefinição. Como não é tematizado, não pode encontrar uma definição apropriada, por fim, o terceiro motivo é que o ser, não obstante isso, é tomado como algo claro e auto-explicativo.

Ao recolocar a questão nesses termos, Heidegger está recusado a metafísica, a dicotomia sujeito X objeto, bem como a condição de Vorhandenheit como relação inicial do Dasein com o mundo ${ }^{3}$. Ele está, na verdade propondo uma reflexão que parte de um ponto muito diferente do que fora dominante até antes de suas próprias reflexôes. Por esse motivo torna-se fundamental para o argumento do autor recolocar a arte num local importante da reflexão filosófica e da história do ser, movimento que seria impossível a partir da perspectiva da estética filosófica - que Heidegger identifica como uma disciplina metafísica.

Esse movimento de recolocar a arte num ponto privilegiado da reflexão filosófica ${ }^{4}$, isto é, relacionar a arte com a experiência do pensamento (perigoso, incerto) e não apenas com a experiência do conhecimento (seguro, determinado) se inicia com a caracterizaçáo da arte como uma origem e culmina na retomada dos escritos de Hölderlin sobre o modo poético como o homem habita o mundo. Como aponta a tradutora portuguesa de Die Ursprung der Kunstwerk, Maria da Conceição Costa (2007) na introdução do livro, "a verdade é artística e a arte poética, na sua essência, fundadora”.

Dito em termos do campo da Comunicaçáo, a experiência com a obra de arte seria, de acordo com Heidegger, uma experiência indeterminada e incerta, uma experiência de retardo do significado (já codificado) em prol de uma abertura reconfiguradora, abertura que possui uma dimensão acontecimental. $\mathrm{O}$ desvelamento do ser, a verdade. Ou seja, seguir o argumento heideggeriano em A origem da obra de arte, implica em relacionar a experiência com a arte da noção de acontecimento (que marca, reconfigura), deixando pouco ou nenhum espaço para uma poética do cotidiano5 ${ }^{5}$, como reivindica Lopes (2006).

O cotidiano não poderia ser poetizado porque, para Heidegger, ele é a condição de possibilidade da Poesia - o que se inicia com a identificação da origem da obra de arte, converte-se numa afirmaçáo sobre a arte como uma origem. É na obra de arte que o autor enxerga o acontecimento da verdade e o cotidiano não poderia oferecer uma seqüência ininterrupta desses acontecimentos. É a arte que origina possibilidades, ela é quem abre o campo dos possíveis, a cada vez, acontece de modo singular e histórico. Ao fazê-lo reinventa os cotidianos e o marca com características.

Teríamos assim que pensar, ao contrário do que é proposto por Lopes (2006), num cotidiano da poética, a fim de examinar os elementos que velam certos acontecimentos da verdade. Se pensarmos essa proposição mais uma vez em termos do campo comunicacional, veremos que sua abrangência sustenta uma proposição como a do filósofo Friedrich Kittler (1999), que propóe pensar o campo de possibilidades inauguradas pelo gramofone (arte de reproduzir o som), cinema (arte de reproduzir a imagem em movimento) e máquina de datilografar (arte de reproduzir a escrita), nas formas cotidianas de experimentar 
o mundo.

Retornando aos argumentos de Heidegger sobre a arte como algo originário nos deparamos com o conflito entre mundo (Welt) e terra (Erde) descrito pelo autor. A dificuldade em apreender o sentido desses termos é grande, uma vez que não se sabe ao certo se eles se tratam de conceitos ou de metáforas utilizadas pelo filósofo para dar conta do processo que quer descrever. Entretanto, é possível fazer uma aproximação com outros pares, tais como: desvelamento $\mathrm{X}$ velamento, ser $\mathrm{X}$ ente, physis X techne.

Esses pares, no entanto, não podem ser tomados como dicotômicos. São pares interdependentes, na realidade. $\mathrm{O}$ monismo característico do pensamento heideggeriano toma os elementos como condições de possibilidade. Nesse sentido, não há desvelamento total, pois quando algum aspecto é desvelado, outras características se escondem. Isso significa que no conflito entre mundo e terra, não há necessidade de superação de um ou outro, mas de um co-pertencimento.

Heidegger, em decorrência disso, refuta fortemente as teses sobre a arte que a explicam a partir da distinçáo entre forma e substância ${ }^{6}$, considerando que a partir dessa perspectiva só podemos falar do ente (apetrecho) e não o ser da obra. Nas proposiçóes feitas para a consolidação da estética da comunicação temos, portanto, um forte argumento contra a fundamentação nas teses aristotélicas ou do pragmatismo de John Dewey. O co-pertencimento a que se refere o filósofo alemão, não pode ser confundido com um modo "ideal de enformar a substância" - embora esse tenha sido o caminho tomado pela filosofia desde a antiguidade clássica. A relaçâo de co-pertencimento entre mundo e terra implica aceitar a tendência da verdade em si entificar (tornar-se ente), para mais tarde desvelar o ser. O Dasein está, portanto, em contato com o ente (terra), sua liberdade consiste em deixar-ser o ser, deixar emergir a obra de arte. A beleza da obra é o seu aparecer.

\section{Dimensão relacional do aparecer (Erscheinen)}

Assim como Heidegger propõe recolocar a reflexão sobre a arte num ponto privilegiado do pensamento filosófico, Martin Seel procura recolocar a Estética numa posição de destaque na filosofia, a partir de uma reorientação para um campo de igual importância da teoria do conhecimento e da filosofia prática, caracterizando a filosofia da arte como uma parte da Estética (e não como algo de menor importância). O ponto de partida de Seel é a filosofia de Adorno, embora não siga a tradição da escola de Frankfurt. Após a sua crítica sobre a falta de uma reflexão sobre a racionalidade estética nos escritos da escola Frankfurt, Seel lança a proposição de pensar o aparecer como elemento básico da estética.

Focando o mote beleza enquanto aparecer da obra, Seel (2005) tenta argumentar em favor de um ponto de vista mais relacional entre arte e experiência, náo de modo a reconduzir o debate para o campo da subjetividade, tampouco de aceitar totalmente a posição heideggeriana sobre a arte como 
acontecimento da verdade, mas de valorizar esse encontro que ocorre entre o objeto estético e percepção estética.

Seel parte de uma descrição do aparecer que é sempre interdependente da multiplicidade de objetos e fenômenos. "Um tipo de objeto estético goza seu caráter distintivo em relação a outros tipos de objeto, com os quais se destaca, que os quais ele se relaciona e com os quais está no processo de troca" (SEEL, 2005 , p. 19) 7 . O autor confere uma dimensão temporal para esta relação, é necessário haver tempo para a emergência do encontro entre objeto e percepção estéticas (uma espécie de frame) e uma dimensão situacional, de modo que haja uma percepção interdependente do objeto e do percebedor, sendo necessário, portanto, focar os aspectos materiais da relação.

A fim de fortalecer suas argumentações em torno da importância da relação entre objeto e percepção estéticas, Seel investe numa perspectiva tanto cultural quanto existencial do aparecer, afirmando que esse se trata de um modo genuinamente humano de se relacionar com o mundo. Um objeto estético seria um objeto no processo do seu aparecer; a percepção estética seria a atenção a esse processo. Para Seel, o que favorece essa atenção ao processo de aparecer é uma dimensão cultural fundamental do homem - "todas as culturas parecem possuir uma noção do drama de sua própria presença” (SEEL, 2005, 37) ${ }^{8}$.

A leitura que o autor faz de Heidegger é interessante. Seel aposta numa interpretaçáo do conflito entre mundo e terra que ocorre em toda obra de arte como uma luta entre aspectos do significado e aspectos materiais, respectivamente. Os aspectos materiais tenderiam a ameaçar o significado, fazendo-o desaparecer (ou seja, velando-o), para depois reaparecer com novos sentidos, experiência que amplia as possibilidades e abre novos mundos (o desvelamento). Esse pôr-se-em-obra da obra está fundamentado num retraimento da terra, isto é dos aspectos materiais que a compóem. Essa convergência com a argumentação heideggeriana, entretanto, não impede Seel de afirmar a posição fundamental da percepção no processo de aparecer.

A percepção estética está aberta para nós em todos os momentos, desde que pressóes internas ou externas não nos neguem a latitude necessária para se engajar nela (...) o dominio da estética não é uma área delimitada próxima de outras áreas da vida, mas uma das possibilidades da vida diante de muitas outras que podemos nos engajar de quando em vez (SEEL, 2005, 20)9.

Isso significa, então, que Seel não está tão convencido da posição que Heidegger confere ao Dasein no seu ensaio sobre a origem da obra de arte. Vale lembrar que Heidegger inicia sua pergunta sobre a obra de arte questionando o caráter coisal da obra, posteriormente o caráter de obra da obra e só então questiona a figura do artista. Seel apresenta, na sua tese, dois elementos fundamentais - de um lado o objeto estético, de outro a percepção estética.

Para Seel, a distinção básica a partir da qual a estética do aparecer retira seu nome está no modo sensório como o objeto é percebido. Estéticos são aqueles encontros nos quais há uma apreensão dos aspectos imagéticos, sonoros ou táteis 
de um objeto, de uma forma mais ou menos diferente daquela forma conceitualmente determinada. E isso pode ocorrer tanto com objetos do cotidiano quanto com os objetos da arte moderna. Náo há forma de percepção ou produção estética que tenha rompido com o modo do aparecer, segundo o autor.

Se cada objeto aparece de formas singulares, a primeira operação deve ser, portanto, entender o que aparece? Seel distingue o perceber algo, do perceber que algo e do perceber como algo para mostrar que é o fato de podermos perceber desses três modos que permite, também, desvincular essas três dimensóes da percepção, de modo que na percepção estética, possamos perceber algo que é conceitualmente determinado de maneira desvinculada a qualquer de suas possíveis determinaçôes, ou, como sugere Kant em relação ao juízo estético, "sem mediação de conceitos".

O importante não são as características apenas do objeto, mas da interação. Assim, o objeto percebido esteticamente se mostra sempre num estado transitório - nada é simplesmente o que é, mas aparece sob a luz de algumas relações. A percepção estética leva em consideração a individualidade fenomênica dos objetos, permitindo que algo esteja presente na diversidade do seu aparecer. Importante para esse tipo de reflexão, portanto, são contrastes, interferências e transiçóes que resistem às descrições, uma vez que são dadas apenas na simultaneidade e, frequentemente, em instantes momentâneos. Normalmente essas qualidades não são apreendidas com um único sentido, mas com o ser total. $\mathrm{O}$ que chega à percepção na apreensão estética é uma interação dos aspectos sensíveis do objeto com uma presença particular em cada caso, a do percebedor.

Percebe-se, desse modo, que Seel pressupóe a separação, um dualismo que concebe um percebedor e um objeto/fenômeno em inter-relação. Na relação entre percepção e objeto estéticos, Seel confere importância significativa ao aspecto ressonante desse encontro. Há uma ocorrência, embora não haja algo ocorrendo, há uma experiência do indeterminado. $\mathrm{O}$ aspecto ressonante significa que o percebedor se perde dentro do mundo que aparece (não das aparências), sendo, portanto, um fenômeno da imanência e não da transcendência. $\mathrm{O}$ ressonante implicaria um auto-render do percebedor frente à sua presença com objeto estético, e não perante a obra de arte - como formula Heidegger ao pensar na essência fundadora da obra de arte.

Por esse motivo é que as teses do autor colaboram com a argumentação de Guimarães (2006) em torno da inserção da experiência estética num contexto específico de ação e comunicação, numa atitude que levaria o sujeito a desenvolver uma "compreensão pragmático-performativa do objeto que aparece”. Essa apropriação feita por Guimarães é importante para o campo comunicacional pelo fato de a compreensão pragmático-performativa poder ser partilhada, não a partir de aspectos proposicionais, mas da fricção mesmo com o "outro", com terceiros - que Seel chamará de comunicação presentificante ${ }^{10}$. Daí a possibilidade de incorporar as proposiçóes de Seel para forçar que um campo de conhecimento, tão recente quanto a Comunicação, se confronte com certos pré-conceitos originários que acabaram por reduzir a comunicação a um tipo de conhecimento sobre a transmissão dos conteúdos. 


\section{Repensar a estética e a hermenêutica no campo da comunicação}

Como sugere Valverde (2007b), qualquer proposição que intente construir uma forma de compreensão da comunicação que incorpore o aspecto estético precisa dialogar com as discussóes já iniciadas pela Estética filosófica. Não se trata apenas de uma "prestação de contas", mas tomando o pensamento heideggeriano como inspiração, para fazer as perguntas que ainda não foram feitas.

Valverde afirma que identificar o papel da reflexão estética na teoria da comunicação significa investigar quais as condiçôes de possibilidade para uma abordagem estética da comunicação, tomando como pressuposto a existência de uma comunicabilidade estética que possibilita toda a comunicação e o aspecto existencial dependente de "um compartilhamento de um sentimento de existência, pelo qual os membros de uma comunidade se reconhecem”. Seu principal ponto de reivindicaçáo é o retorno a uma espécie de "hermenêutica da sensibilidade", apoiada sobretudo na obra de Merleau-Ponty e Paul Ricoeur - que foram extremamente influenciados pela repercussão do pensamento heideggeriano na França.

É interessante que o movimento contrário - um afastamento entre estética e hermenêutica - tenha tido início na própria Alemanha, em meados da década de 80, cujos representantes principais estão entre aqueles que mais sofreram a influência da Hermenêutica de Heiddeger, Hans-Georg Gadamer e Hans Robert Jauss. O autor Hans Ulrich Gumbrecht, que tem sido retomado nos estudos da campo da comunicação pela sua teoria das materialidades e discussão sobre o campo não-hermenêutico, é um dos líderes desse movimento. $\mathrm{O}$ diálogo feito por Felinto \& Andrade (2004) com as idéias do autor retoma da dimensão material da cultura de modo a valorizar, na experiência, os choques e contatos com os objetos e fenômenos do mundo.

Entretanto, embora haja características específicas da apreensão estética e hermenêutica dos objetos do mundo, não há motivos para criar uma dicotomia entre as duas disciplinas filosóficas, sobretudo quando pretende-se fazê-las dialogar com o universo do campo comunicacional contemporâneo. Como coloca Seel , "os objetos da arte são media de uma experiência, que brincam com o processo de entendimento e que não apenas buscam o entendimento como resultado"11(SEEL, 2007, p. 38). A própria Hermenêutica não se colocou, apenas, com uma disciplina de interpretação de textos, mas como uma disciplina do entendimento em sentido amplo.

Seel vai argumentar, ainda, que esse gradual afastamento entre estética e hermenêutica, no contexto alemão, se desenvolveu a partir dos escritos de filósofos como Rüdiger Bubner, Karl Heinz Bohrer, Jochen Hörisch e Christoph Menke, além do próprio Hans Ulrich Gumbrecht. "Houve um tempo - no áureo período do grupo de pesquisa Poetik und Hermenutik -, no qual a combinação de palavras que dá título ao meu texto, era quase automática. Este é de qualquer modo, um tempo já passado (SEEL, 2007, p. 27)"12.

O próprio Adorno teria, mais tarde, criticado a junção entre objeto hermenêutico e objeto estético na sua Teoria Estética afirmando que tal comparação 
só "compreenderia, no estado atual, sua incompreensibilidade". Seel pretende reatar a tradiçáo hermenêutica da estética a partir do questionamento sobre a existência de uma sujeição de uma disciplina sobre a outra, a partir do exame de três fenômenos distintos: o estudo da natureza, do esporte e das artes.

Em primeiro lugar, na experiência com a natureza teria-se uma das primeiras razóes para separar a tradição hermenêutica da estética. Seel (2007) afirma que muitos consideram que não haveria nada pare ser entendido na percepção da natureza, portanto, não haveria componente hermenêutico. Também o poeta Alberto Caeiro, heterônimo de Fernando Pessoa, acusava a prescindibilidade de qualquer entendimento para a experiência com a natureza. As propriedades estéticas da beleza da natureza implicam que há muito para perceber com os sentidos, mas pouco para compreender. $\mathrm{O}$ que significa que uma Estética vinculada a Hermenêutica seria incompetente para tratar desses assuntos.

Entretanto, táo logo gozamos dessa beleza natural, explica Seel, nos apropriamos também de uma dimensão compreensiva que nos transcende. A imersão frente à beleza natural e adjacências nos dá tempo para o momento, espaço para o inesperado e para a liberdade de comportamento. Embora possam objetar que esses são argumentos para o sentido que a nossa sociedade dá à experiência com a natureza, Seel entende que esses aspectos fazem parte do fenômeno beleza natural. É verdade que a prática estética não é apenas uma prática do entendimento, mas ela não deixa de ser uma prática. Isso significa dizer que há uma dimensão compreensiva na prática estética que permite a entrada da hermenêutica.

O segundo fenômeno a ser analisado é o esporte: Seel dialoga diretamente com a proposta de Gumbrecht. Para Seel, há duas teses principais na argumentação do autor: uma negativa, que pontua que para os espectadores de esportes coletivo, o esporte não é signo de nada, nem alegoria. Ele até poderia ser uma representação da luta titânica ou do movimento de expansão capitalista mas somente para interpretação profissional, e não para a experiência dos espectadores. A tese positiva afirma que o espectador de esportes modernos participa da produção de um acontecimento indeterminável. Seel a expóe da seguinte maneira:

Porque a prática esportiva em si mesma não oferece nenhum significado transcendente, nada diminui no momento do seu desempenho. Isso permite ao espectador uma ruptura da continuidade da suas vidas - ruptura que, como a da arte, não os força a refletir sobre o jogo de suas próprias vidas. Apesar disso, as pessoas dão o seu dinheiro por algo: a possibilidade de celebração das incertezas da vida (SEEL, 2007, p. 32)13.

Para Seel, os aspectos finais da explicação da tese de Gumbrecht mostram, outra vez, que não há motivo para separar a hermenêutica do problema estético. Essa oportunidade de celebrar o indeterminável da vida pode ser uma porta de entrada da hermenêutica, desde que não se entenda a hermenêutica como uma mera disciplina de interpretação dos textos, mas como propunham Heidegger e Gadamer, como uma geral compreensão do entendimento. 
A prova decisiva para manter hermenêutica e estética como parceiras seriam os fenômenos ligados a arte. Embora argumente-se que as obras de arte são elementos complexos dos quais os processos de interpretação e entendimento são apenas pequenas partes e que frente a abertura e diversidade da obra de arte a hermenêutica nada poderia apreender (na sua fixação pelo sentido, a hermenêutica estaria fadada a tentar tornar o incomensurável em mensurável), Seel vai defender que essa crítica só faz sentido quando se possui uma compreensão restrita do "sentido". Mas se a experiência estética é entendida como um processo cujo fim está em seu próprio movimento, um livre movimento cujo sentido e objetivo está em si mesmo, o movimento de perder-se na própria obra, as coisas começariam a mudar. Entáo o entendimento não é uma faculdade para identificar o objeto da experiência e do sentido, mas é o movimento material de adaptar-se a obra (a construção, gesto...) pelos quais aparecem os meios de apresentação da obra. Esse relacionar-se com objeto é uma faculdade do entendimento.

Para que essa reabilitação entre estética e hermenêutica de fato ocorra, seria preciso desfazer o postulado de que a apreensão empática e reflexiva da arte seriam impossíveis conjuntamente (postulado que não foi formulado pela hermenêutica). Seria necessário oferecer um lugar de maior destaque à experiência estética - ela não é apenas uma explicação sobre o sentido da arte - uma vez que ela nos coloca num processo que não conhece finalidade porque é um jogo com a percepção e da percepção do presente. Certamente Heidegger estaria certo na sua afirmação sobre ser no combate entre terra e mundo que o pôr-se-em-obra da obra de arte de manifestaria.

Identificando em Heidegger e Seel chaves para pensar incidências da reflexão estética e hermenêutica na cultura contemporânea e formas relacioná-las aos argumentos levantados pelos teóricos da comunicação, apostamos numa reconfiguração do campo comunicacional a partir da temática estético-hermenêutica, de modo que o paradigmas transmissivo ou da significação sejam revistos e revisados.

\section{Notas}

${ }^{1}$ Uma versão preliminar desse artigo foi apresentado no VIII SOPCOM - Ibérico, na Universidade Lusófona, em Lisboa, abril de 2009. Agradecemos pelas contribuições a Maria Tereza Cruz e Cleomar Rocha, bem como aos participantes do GT de Estética, arte e design. A configuração atual do artigo é inédita.

2 A COMPÓS, Associação Nacional dos Programas de Pós-Graduação em Comunicação do Brasil, criou, em 2007, um grupo de trabalho que congrega pesquisadores preocupados com a interface estética e comunicação sob a rubrica estéticas da comunicação. Em nossa compreensão, o plural utilizado no nome desse fórum de discussão evidencia a salutar heterogeneidade de concepçóes que permeia as reflexões.

${ }^{3}$ As expressões utilizadas por Heidegger são pouco usuais, mesmo no idioma alemão. Vorhandenheit, por exemplo, é o termo que o autor utiliza para descrever uma relação 
que está "frente a mão" e se opôe ao Zuhandenheit relaçôes "a mão". São metáforas usadas para demonstrar que na relação do homem com o mundo, estamos falando de Zuhandenheit e não de Vorhandenheit.

${ }^{4}$ Platão havia colocado a reflexão sobre a arte numa posição muito inferior ao conhecimento filosófico, em A República, de modo que a tradição posterior tornou-se devedora da formulação platônica. Friedrich Nietzsche foi um dos pensadores que buscou reverter esse quadro bem como Heidegger, ao seu próprio modo.

${ }^{5}$ A poética do cotidiano, a que se refere Lopes (2006), se preocupa com o que é comum e tenta oferecer como possibilidade de existência prática do sujeito, um modo de intervir no mundo. A questão é que essa possibilidade de intervir no mundo é pano de fundo para desvelamento, que tende cada vez mais a se retrair quanto mais o Dasein busca por ele.

${ }^{6}$ Além dessa posição, o autor refuta também as teorias que afirmam que a obra de arte é "uma coisa a qual se adere algo de outro", um suporte para suas características, e as que afirmam que ela é "a unidade de uma multiplicidade de dados no sentido".

${ }^{7}$ No original, one type of aesthetic object enjoys its distinctiveness only in relation to other types, against which it stands out, to which it is related, with which it is in a process of exchange.

${ }^{8}$ All cultures seem to have a sense of the drama of their own presence.

${ }^{9}$ Aesthetic perception is open to us at all times, as long as external or internal pressure does not deny us the latitude necessary for engaging in it (...) The domain of the aesthetic is not a delimited are alongside other areas of life, but one of life's possibilities among others that we can take up from time to time.

${ }^{10}$ Modo de articulação do sentido, vinculado a uma situação e baseado em um conjunto de pressuposiçôes partilhadas, permite alargar e corrigir uma pré-compreensão dada, ou ainda, introduzir, de maneira provocadora, um ponto de vista desviante.

${ }^{11}$ Objekte der Kunst sind Medien einer Erfahrung, die sich als ein Prozess des Verstehens abspielt, der nicht auf das Resultat eines Verstandenen zielt.

${ }^{12}$ Es hat eine Zeit gegeben - es waren die seligen Zeiten der Forschergruppe Poetik und Hermeneutik -, in der die Wortverbindung, die hier meinen Titel bildet, fast selbstverständlich war. Das ist jedoch seit längerem vorbei.

13 Weil die sportliche Performance keinen über sich selbst hinausweisenden Sinn vermittelt, lenkt nichts von der Zeit ihrer Darbietung ab. Das erlaubt es den Zuschaeurn, eine kollektive Auszeit von den Kontinuitäten ihres Lebens zu nehmen - eine Auszeit die sie nicht, wie diejenige der Kunst, über das Spiel ihres Lebens zu reflektieren zwingt. Trotzdem kriegen die Leute etwas für ihr Geld: die Gelegenheit zu einer Zelebration der Ungewissheiten ihres Lebens. 


\section{Referências Bibliográficas}

FELINTO, Erick \& ANDRADE, Vinícius. (2005) A vida dos objetos: um diálogo com o pensamento da materialidade da comunicação. Contemporânea, volume 03, n.01, janeiro/junho, p. 75 - 94.

GUIMARÁES, César. (2006). O que ainda podemos esperar da experiência estética?. In: GUIMARÃES, César et al (org.). Comunicação e Experiência Estética. Belo Horizonte: Editora UFMG, pp. 13 - 26.

HEIDEGGER, Martin. A origem da obra de arte. (1950) Tradução de Maria da Conceição Costa. Lisboa: Ediçôes 70, 2007.

. Sein und Zeit. (1927). Tübingen: Max Niemeyer Verlag, 2007.

KITTLER, Friedrich. (1999). Gramophone, film and typewriter. Traduzido do alemão por Geoffrey Winthrop-Young e Michael Wutz. Stanford: Stanford University Press.

LOPES, Denílson. (2008). A delicadeza-estética, experiência e paisagens. Brasília: Editora da UNB.

(2006). Da estética da comunicaçáo a uma poética do cotidiano. In: GUIMARÁES, César et al (org.). Comunicação e Experiência Estética. Belo Horizonte: Editora UFMG, p. 117 - 150.

SEEL, Martin. (2005). Aesthetics of Appearing. Traduzido do alemão por John Farrell. Stanford: Stanford University Press.

(2007). Ästhetik und Hermeneutik: gegen eine voreilige

Verabschiedung. In: Die Macht des Erscheinens. Frankfurt: Suhrkamp Verlag, p. $27-38$.

VALVERDE, Monclar. (2007). Estética da Comunicaçâo - sentido, forma e valor nas cenas da cultura. Salvador: Editora Quarteto. 